\section{India demands "sharp break" from current practices}

In a strong statement that reflected many of the demands being made by other member countries of the Group of 77 , the head of the Indian delegation to UNCSTD strongly criticised the way in which current forms of assistance from the developed world tends to increase the dependence of the developing world and to accentuate disparities in scientific and technological capabilities.

"A sharp break from this pattern so as to lead to a better sharing of the capabilities and to a lessening of global income disparities is called for"' Dr D I Lakdawala, deputy chairman of India's Planning Commission, told the conference.

The experiences of two International Development Decades had led to a realisation among developing countries that the present structure of science and technology could not fulfil the types of promises that had been made earlier, such as providing growth with social justice and fulfilling minimum basic needs, he said.

Pointing out that a science and technology plan had been a central feature of Indian economic planning in recent years, Dr Lakdawals said that the Indian experience stressed, in particular, the need for a proper delivery and extension system to ensure that the fruits of science and technology became widely available.

"It also underlines the need for a proper infrastructure and appropriate economic policies and fiscal incentives to encourage application of scientific and technological discoveries on the farms and in the factories. And in this task developing countries can greatly benefit from mutual cooperation,"' he said.

In the past, a purely sectoral approach to issues such as technology transfer or access to information had often failed to develop endogenous capability in science and technology and to bring a proper share of benefits to developing countries.

It is essential that in future the selection of sectors and programmes and the methods of their execution must fully reflect the preferences of the developing countries concerned. The policy should be to build up full endogenous capabilities so that in the name of immediate benefit, dependence is not perpetuated and selfreliance is fostered."

It was along these lines that the countries of the Group of 77 had constructed the draft programme of action being debated by the conference, to which India had given full support.

- India's efforts on primary health care see page 716

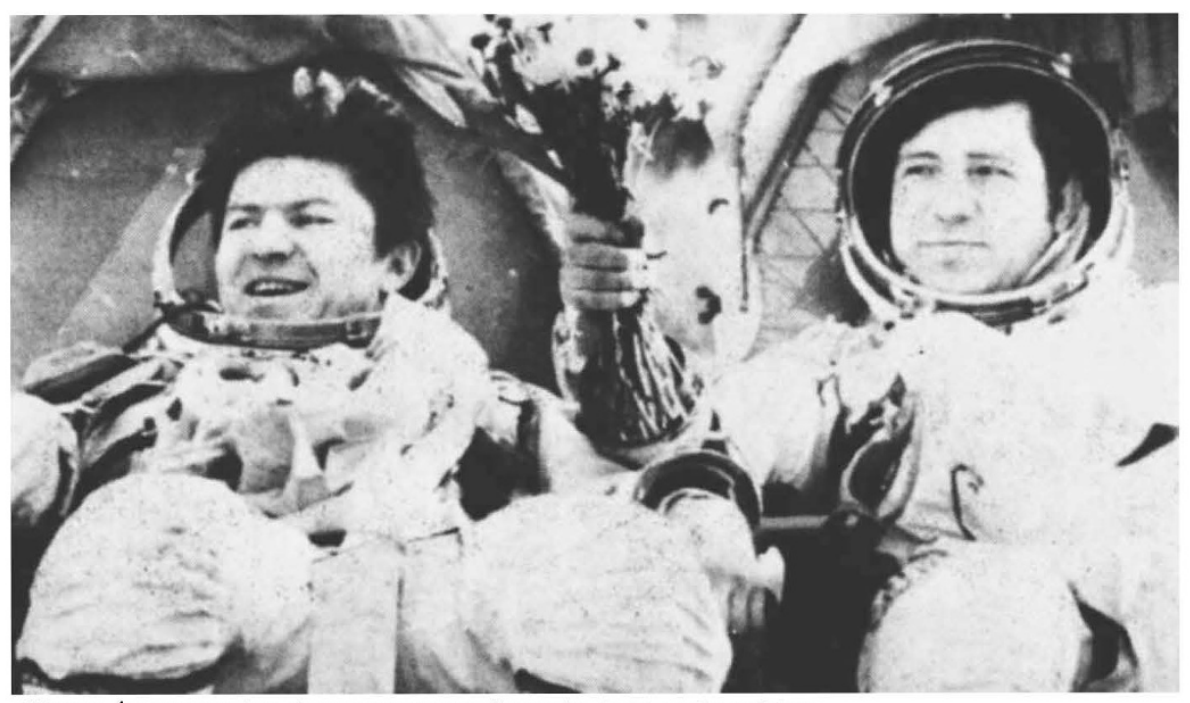

Happy home-coming for cosmonauts Ryumin (left) and Lyakhov

\title{
Soviet spacemen return to Earth
}

Long-term orbital missions such as that completed recently by cosmonauts Vladimir Lyakhov and Valerii Ryumin, will be the mainstay of the Soviet manned space programme for the foreseeable future, according to a recent statement of Academician R.Z. Sagdeev, Director of the Institute of Space Studies. Priority will be given, he said, to establishing how long a cosmonaut can remain in orbit without damage to his health - an important preliminary to the establishment of the permantently-manned orbital stations predicted by Tsionkovskii.

Not surprisingly, the programme of the mission has placed considerable emphasis on physical and psychological health. Prophylactic measures ranged from the use of the Chibis pressure-suit to simulate the cardiovascular tone of normal gravity to the visit of pop-singer Valentina Ignateva to the mission control centre to sing to the crew. No medical surprises were expected from the mission; on a previous mission there was considerable excitement when the 120-day deadline was passed, since this is the lifespan of red corpuscles. According to one of the medical team, Dr Anatolii Egorov, this time it was simply a matter of collecting statistical data of the body's reaction to gradually extended periods of weightlessness. Owing to the crew's "exceptionally conscientious" attitude to exercise, their health remained excellent.

The experimental programmes of the mission took the now standard forms -

\section{UK tram lovers book Shuttle space}

A call from the Tramway Museum in Crich, Derbyshire, has proved unusually fruitful for Professor Eric Laithwaite of Imperial College, London. Enthusiasts there have booked room on board a 1982 Space Shuttle flight and given their 1.5 cubic feet of space to Professor Laithwaite. "It's like a big birthday present", he said.

$\mathrm{He}$ will be designing an experiment to observe the behaviour of a precessing aserophysical and geophysical observations, "Zero-gravity technology", including a new aluminium-spraying experiment, and biological and genetic experiments. Towards the end of the mission, they assembled an orbiting radiotelescope, inaugurating, in Pravda words "a new stage in space research, that of extra-atmospheric astronomy".

Ironically, however, while the spacebiologists seek ways to extend the length of manned missions, there are hints that certain planners would like to reduce the human involvement. In a radio interview, one of the designers of the radio-telescope, identified only by name and patronymic as Valentin Petrovich, said that in the future all such equipment would ultimately be automated, although "in the first stages of development ... the role of man is very great"'. Likewise, Dr Konstantin Feoktistov, a frequent spokesman for the programme stressed that the majority of the crew's time is taken up with communications, routine housekeeping and maintenance, medical checks and the need to keep fit leaving little time to carry out the experiments which are, presumably, the main object of having a space station at all. "It follows that more use should be made of automation", he said, as far as the experiments are concerned, with the crew simply "correcting the programmes, repairing and servicing equipment, and so on".

Vera Rich

gyroscope in zero gravity. This, he believes, may show that inertial mass and gravitational mass were not the same and would demonstrate an effect that could have enormous benefits in developing new propulsion systems.

The museum has booked the space on the Shuttle as a way of publicising itself and of celebrating the centenary of electric traction. 